NBER WORKING PAPER SERIES

\title{
US FACULTY PATENTING: INSIDE AND OUTSIDE THE UNIVERSITY
}

\author{
Jerry Thursby \\ Anne Fuller \\ Marie Thursby \\ Working Paper 13256 \\ http://www.nber.org/papers/w13256
}

\author{
NATIONAL BUREAU OF ECONOMIC RESEARCH \\ 1050 Massachusetts Avenue \\ Cambridge, MA 02138 \\ July 2007
}

The authors gratefully acknowledge research support from the Ewing Marion Kauffman Foundation. Fuller acknowledges support from the Alan and Mildred Peterson Foundation, and M. Thursby acknowledges support from the National Science Foundation. Participants of seminars at University College London, London Business School, the 2006 Technology Transfer Society meeting and 2006 Roundtable on Engineering Entrepreneurship Research at Georgia Institute of Technology provided useful comments. We thank Bhaven Sampat for providing access to his patent database. The views expressed herein are those of the author(s) and do not necessarily reflect the views of the National Bureau of Economic Research.

(C) 2007 by Jerry Thursby, Anne Fuller, and Marie Thursby. All rights reserved. Short sections of text, not to exceed two paragraphs, may be quoted without explicit permission provided that full credit, including $\odot$ notice, is given to the source. 
US Faculty Patenting: Inside and Outside the University

Jerry Thursby, Anne Fuller, and Marie Thursby

NBER Working Paper No. 13256

July 2007

JEL No. L24,L26,O31,O34,O38

\begin{abstract}
$\underline{\text { ABSTRACT }}$
This paper examines the empirical anomaly that in a sample of 5811 patents on which US faculty are listed as inventors, $26 \%$ of the patents are assigned solely to firms rather than to the faculty member's university as is dictated by US university employment policies or the Bayh Dole Act. In this paper we estimate a series of probability models of assignment as a function of patent characteristics, university policy, and inventor fields in order to examine the extent to which outside assignment is nefarious or comes from legitimate activities, such as consulting. Patents assigned to firms (whether established or start-ups with inventor as principal) are less basic than those assigned to universities suggesting these patents result from faculty consulting. A higher inventor share increases the likelihood of university assignment as compared with assignment to a firm in which the inventor is a principal but it has no effect on consulting with established firms versus assignment to the university. Faculty in the physical sciences and engineering are more likely to assign their patents to established firms than those in biological sciences.

Jerry Thursby

Dept. of Economics

Emory University

Atlanta, GA 30322

jthursb@emory.edu

Anne Fuller

Georgia Institute of Technology

800 W Peachtree St NW

Atlanta, Georiga 30332

anne.fuller@mgt.gatech.edu

Marie Thursby

College of Management

Georgia Institute of Technology

800 West Peachtree street, NW

Atlanta, GA 30332-0520

and NBER

marie.thursby@mgt.gatech.edu
\end{abstract}




\section{Introduction}

The role of universities in industrial innovation has long been a topic of keen interest to academics, practitioners, and policy makers. Despite extensive research, there is still much that we do not understand, in large part because knowledge flows do not always leave a publicly accessible "paper trail.” In this regard, patents are a useful tool as citations to prior patents or publications provide such a trail. Thus much of our understanding of the impact of academic research on industrial innovation comes from the literature on spillovers, which is based on citations to university assigned patents (e.g., Henderson et al., 1998; Jaffe, 1989; Jaffe et al., 1993; Trajtenberg et al., 1997). The contribution of other mechanisms such as consulting, sponsored research, and licensing has relied on the analysis of proprietary data from surveys or interviews (e.g., Cohen et al., 1998; Mansfield, 1995; Mowery et al., 2001; Thursby et al., 2001; Thursby and Thursby, 2004; Zucker and Darby, 2006). A key insight from the latter stream of research is that faculty themselves, rather than their disembodied work, often play a critical role in universityindustry technology transfer. In this paper, we focus on faculty inventors and show that patent data, when collected not by assignee, but by inventor, provide a more comprehensive picture of the contribution of universities to industrial patenting than is commonly understood.

We examine a sample of 5811 US patents on which one or more of the inventors were faculty members of $87 \mathrm{PhD}$ granting departments of Research I universities at the time of patent application. Only 62.4 percent of these patents were assigned solely to universities. This is a remarkably low percentage since employment contracts in US universities specify that inventions resulting from faculty research belong to the university when university resources are used in the research. Further, the Bayh-Dole Act of 1980 allows universities to own and patent the intellectual property (IP) resulting from federally-funded research and, in the case of industry sponsored research, US universities historically have insisted on ownership (Thursby et al., 2001).

An immediate implication of this low percentage is that the common practice of identifying US university patents by institutional assignment misses a surprisingly large percentage of inventive activity by faculty in US universities. Others have found a similar phenomenon in Europe where the majority of patents listing faculty as inventors are assigned outside the inventors' universities (Crespi et al., 2006; Geuna and Nesta, 2006; Saragossi and van Pottelsberghe de la Potterie, 2003). It is important to recognize, however, that until recently professor privilege (faculty ownership of inventions) was common in Europe so that inventors typically assigned patent rights to their research sponsors rather than to their universities (Geuna and Nesta 2006). This of course cannot explain the phenomenon in the US.

It is therefore important to ask why the faculty in our data assign patents outside the university. While patents assigned outside may legitimately belong to the university, our interviews with university technology transfer, industry personnel and faculty inventors suggest that the bulk of this assignment re- 
sults from faculty consulting. In this paper we estimate a series of probability models of assignment as a function of patent, university, and inventor characteristics in order to examine the extent to which outside assignment is nefarious or comes from legitimate activities, such as consulting.

Our main regression is a multinomial logit model in which assignment can be of four types: 1) assignment to a university, 2) assignment to a firm in which the inventor is a principal, 3) assignment to a firm in which the inventor is not a principal, or 4) the patent is unassigned and therefore owned by the inventor(s). Any type of assignment other than assignment to a university can result from a number of scenarios, some legitimate and some not. In our analysis we rely on patent characteristics to make inferences in this regard. In particular, we argue that where the research is conducted determines legitimate assignment. Since university research tends to be more basic or fundamental than industry research, we would expect patents based on research in university labs to be more basic than those resulting from consulting in firm labs. Thus if firm-assigned patents are more incremental than university-assigned patents, we infer that they are the result of consulting. In contrast, if firm-assigned patents are similar to or more fundamental than those assigned to universities, the inference is that they may have emanated from university labs. In the regression analysis, we find that the patents assigned to firms are indeed more incremental than those assigned to universities. Thus, our results support Thursby and Thursby's (2005) conjecture that firm assignment is primarily the result of consulting. Moreover, we show that while some firm assignments may be nefarious, simply assuming that outside assignment represents inventor circumvention of university policy, as do Audretsch et al. (2006) and Markman et al. (2006) can be misleading. ${ }^{1}$

From a policy perspective, one of the interesting university factors we consider is the share of revenue from licensing that accrues to the inventor when inventions are assigned to and licensed by the university. If, as in Jensen and Thursby (2001) and Lach and Schankerman (2004) faculty respond to financial incentives associated with licensing, faculty would be more likely to disclose inventions to the university the higher is their share of any revenue the university earns from licensing those inventions. Further, in Jensen et al.'s (2006) theoretical analysis of consulting, faculty are less likely to consult the higher is the inventor's share of revenue. In our regression analysis, a higher inventor share increases the likelihood of university assignment as compared with assignment to a firm in which the inventor is a principal but it has no effect on assignment to a university versus other firms or on ownership of the patent by the inventor (unassigned patents). This suggests two possibilities. First, faculty in low share universities may be more willing to seek outside remuneration via assignment to a start-up firm in which

\footnotetext{
${ }^{1}$ In Audretsch et al.'s (2006) survey of scientists funded by the National Cancer Institute nearly 30\% of the faculty inventors had at least one patent assigned to a firm rather than a university. Markman et al.'s (2006) study of patents of faculty in 54 universities finds that 33\% of patents are assigned outside the university. Both studies assume these assignment involve circumvention of the university's technology transfer office. Thursby and Thursby (2005) report that $29 \%$ of the patents in their sample had been assigned to firms.
} 
they are a principal. ${ }^{2}$ Second, revenue shares may have little if any effect on start-up activity, but rather simply reduce the number of inventions that are disclosed to the university. Thus, our results on shares may reflect either or both effects.

We also find significant differences between faculty in the physical sciences and engineering versus those in biological sciences and between faculty in high quality versus lower quality departments. Significant differences are found between assignment by faculty in public versus private universities and between universities in urban versus rural locations.

The work closest to ours is Jensen et al. (2006) which presents a theoretical model of faculty research and consulting, as well as an empirical analysis of faculty publications and patents from 8 US Research I universities. Their analysis differs substantially, not only in its theoretical focus, but also consideration of government and industrial decisions regarding funding for the faculty member's university research agenda.

In Section 2, we discuss the various scenarios in which faculty patents might be assigned outside the university and make the case that assignment and patent characteristics should be related. Section 3 describes the matching process used to create the sample and Section 4 provides a descriptive analysis of the sample. Section 5 presents the econometric models and results. Section 6 concludes.

\section{Patenting by University Faculty}

The passage of the Bayh-Dole Act in 1980 contributed to a landscape of federal court cases and scientific developments (particularly in biotechnology) in which universities have increased their claims on intellectual property (Mowery et al., 2001). The Act gave US universities the right to own and license the results from federally funded research. In return for this right, the university is required to file for patent protection for patentable inventions and to share a portion of any license revenue with the inventor.

Since then there has been a dramatic growth in university licensing through university technology transfer offices (TTO). These are the offices responsible for evaluating inventions and applying for patents. They are, however, dependent on university researchers to disclose when they think they have a research result with commercial potential. With few exceptions university employment contracts require that employees disclose such information to the TTO as the university owns patentable research based on university resources. ${ }^{3}$ Not surprisingly, however, the TTO personnel interviewed in an earlier study indicated that they believe less than half of the faculty inventions with commercial potential are disclosed to their office (Thursby et al., 2001). In some cases faculty may not realize the commercial potential of their

\footnotetext{
${ }^{2}$ Di Gregorio and Shane (2003) find an inverse relationship between start-up activity and inventor share. This result differs from ours in that they consider only inventions that are owned by the university.

${ }^{3}$ To our knowledge, the University of Wisconsin is the only major research university to allow for faculty ownership but this ownership does not extend to federally funded inventions.
} 
ideas, but often they do not disclose inventions because they are unwilling to become involved in the university licensing process. Some faculty may prefer not to become involved in patenting and commercialization altogether, but some who are interested in commercialization may avoid the TTO because they consider the office difficult to work with or they may simply want to avoid foregoing the share of revenue from commercialization that would accrue to the university or TTO (Thursby and Thursby, 2005;

Audretsch et al., 2006). Thus a portion of the patents in our data that are assigned to firms may be inventions that emanated from university labs and that are illegitimately assigned.

We interviewed TTO professionals, industry R\&D personnel and faculty inventors and asked for their explanation for the outside assignments. The primary reason given by all three groups was consulting. As such, the research did not use university resources. ${ }^{4}$ For start-up companies that are originally based on a faculty member's research, it is common for the inventor to serve as a board member or scientific advisor and spend time in the company. In this case, our interviews showed that although the original patent(s) may be licensed from the university, the follow-on patents on research conducted in the start-up are legitimately assigned to it. Further, our discussions indicated that continued faculty consulting is considered vital to the commercialization efforts of the university invention (Fuller and Thursby, 2007).

There are also cases where patents resulting from projects using university resources might be legitimately assigned outside the university. Typically TTOs patent only a portion of the inventions disclosed to them, effectively shelving those that they have no interest in licensing (Macho-Stadler et al, 2005). In the case of shelved disclosures, the TTO may decide to turn over ownership of the invention to the inventor. In our database, 5.6 percent of the inventions are unassigned, which means that the invention is owned by the inventor (though not all of these are likely to be shelved inventions). Also a portion of the assignments to firms with inventors as principals may be shelved patents that the inventor assigned to her/his start-up. Finally, when university research is sponsored by a company, it is possible for resulting patents to be assigned to both the university and the firm. If the company sponsoring the research has considerable background IP for the research, the university may agree on sole assignment to the firm. In our regression analysis, we exclude patents with joint assignments.

If the research activity is consulting then, according to our interviews, assignment will be to the firm for which the consulting was conducted. If the consulting is within the limits of the number of days allowed by the university, then the activity and assignment are legitimate. Note, as well, that consulting with firms in which the inventor is a principal is legitimate. Moreover, as shown by Mansfield's survey (1995), consulting projects are generally more incremental (less fundamental or basic) than those originat-

\footnotetext{
${ }^{4}$ In our interviews with university licensing professionals, we discovered that increasingly university policies include a clause stating that faculty should not enter into contracts that violate their employment agreement. Thus faculty are being advised against sharing IP developed in their labs outside the formal technology transfer channels.
} 
ing in university labs, so that the resulting patents should be more incremental than those assigned to the university. In other words, if the research activity is consulting, then we would expect the patent to be assigned to a firm and to be more incremental than university assigned patents.

In contrast, if firm-assigned patents rightly belong to the university, the underlying research will have been conducted in a university lab. Unless the faculty members who circumvent the university TTO conduct research that differs systematically from the research of those faculty members who disclose to the TTO, these patents should have the same characteristics as patents assigned to the university. This along with Mansfield's results suggests that university-assigned patents and illegitimate firm-assigned patents would be more basic than the firm-assigned patents associated with consulting. If faculty circumvent the TTO with some patents and not others, the natural assumption is that they circumvent the process for their most important patents rather than the more incremental ones. Thus a finding that firm-assigned patents generally are more incremental than university assigned patents would lead us to conclude that the assignments are legitimate. Note that it may be legitimate because it reflects consulting or it may reflect patents on inventions that the TTO deemed were unimportant. The latter may be included among the unassigned patents in our data.

\section{Sample Creation}

To create a sample of faculty patents we matched the last names of the 34,202 scientists and engineers in Ph.D. granting departments of the 87 US Research I Universities in 1993 with names of inventors on US patents. ${ }^{5}$ The faculty names are from the National Research Council (1995). By area, 35.9\% were in the physical sciences, $24.3 \%$ in engineering and 39.8\% in biological sciences. We compare faculty names with inventor names listed in the National Bureau of Economic Research Patent Database. This database provides not only inventor names and locations but also measures of the importance and generality of patents (Hall et al., 2001). To make our problem manageable we use the NBER patent database only for those patents applied for in 1993 and/or granted in 1997 or 1999 (after eliminating duplicates). Since the NBER patent database includes only patents granted by 1999 we supplement that data with all patents granted in $2004 .{ }^{6}$ From the NRC survey we know that a faculty member is at a respective university in 1993 (the year of the survey). For any patent application year other than 1993, we had to independently verify that the faculty member was still associated with their university of record. Thus our choice of patents applied for in 1993 greatly reduced our data collection efforts. Using patents granted in

\footnotetext{
${ }^{5}$ To reduce this problem to a manageable level, our approach was, primarily, a match of faculty with inventors located in the same state as the university. For example, we match inventors in Massachusetts with the R1 universities in Massachusetts. In those states with universities located close to state borders we also include inventors in those bordering states.

${ }^{6}$ This latter data was made available to us by Professor Bhaven Sampat.
} 
1997, 1999 and 2004 gives us a distribution of patent applications across most years from the early 1990's until 2004 (see Table 1). From this initial match we eliminated those for whom first and middle names or initials did not match. Unfortunately, it is not common for either the NRC or the patent office lists to include complete first, middle and last names, and, in some cases, we had only first and middle initials. We then eliminated common names. Our elimination filter was conditional on whether or not we had more than initials for first names and/or middle names; that is, the filter was less dense when we had more than initials. We further reduced the file by calculating the distance between the zip code of the inventor's city and the zip code of the faculty member's university. We eliminated matches where the distance was more than 50 miles. In our data the average zip code distance is less than 7 miles.

(Insert Table 1 about here)

Our procedure for verifying institutional affiliation for inventors on applications filed in years other than 1993 was the following. If the assignment was to the inventor's 1993 university we assumed the inventor was with the university. If the assignment was not to that university, we used a combination of web searches and the faculty listing in the National Faculty Directory to verify affiliation. If we determined that a faculty member was on the faculty in any year after 1993 we assumed she was on the faculty in the intervening years between 1993 and the latter year. A more detailed description of our selection algorithm is provided in the Appendix. ${ }^{7}$

Our sample purposely excludes faculty who do not patent. Our interests are only in those faculty whose work can result in commercializable inventions. By restricting our sample to those who successfully patent we have clearly excluded any faculty whose work is not of immediate commercial relevance to industry. We have also excluded faculty whose work might be of interest to industry but has not resulted in patentable and patented inventions. We have no way of separating faculty whose work is close to the interests of industry but who do not patent from those whose work is not of commercial interest to industry.

\section{Tabulations and Descriptive Analysis}

Our matching process produced 6472 patent/inventor pairs, 5818 unique patents and 2900 different inventors. A single patent was held by $56.2 \%$ of the inventors, $19.4 \%$ had 2 patents, $9.3 \%$ had 3 patents and $15.0 \%$ had 4 or more including a dozen inventors with 20 or more patents each.

Patent assignments were examined and assignees were categorized as follows:

1. assigned to not-for-profit organizations,

2. assigned to for-profit firms,

3. unassigned,

\footnotetext{
${ }^{7}$ We did not employ the Soundex name matching methodology of Trajtenberg, Shiff \& Melamed (2006) since we are interested in a random sample of faculty patents rather than the universe of a particular faculty members patents.
} 
4. assigned to both firms and non-profits,

5. assigned to the federal government or the government and non-profits.

Since the not-for-profit organizations are almost always a university or university hospital we shall henceforth refer to not-for-profit assignments as university assignments. Six hundred and twenty-one (10.7\%) patents had 2 or more assignees. For 7 of the patents the assignee could not be categorized. These seven patents are dropped from the sample.

Table 1 gives the number of patent applications by year and the assignment percentages according to this categorization. ${ }^{8}$ Across all years $26 \%$ of patent assignments are solely to firms while $62.4 \%$ are assigned solely to universities. The percentage assigned to firms increases over the years of the sample and the percentage assigned to universities falls accordingly. The unassigned and federal government assignments are relatively stable.

\section{(Insert Table 2 about here)}

Table 2 tabulates patent/inventor pairs by the major program area of the inventors (biological sciences, engineering and physical sciences). Note that the point of reference here is the patent/inventor pair, thus the assignment percentages in Table 2 differ slightly from those in Table 1 where the point of reference is the patent. Patent/inventor pairs are least likely to come from the physical sciences: $25.4 \%$ of the pairs are from inventors from physical sciences while 35.7\% of faculty in the NRC study are in the physical sciences. Engineering faculty account for $24.3 \%$ of the NRC faculty, but they account for $38.9 \%$ of the pairs in our sample. Biological sciences are 39.8\% of the NRC faculty, and they account for 35.7\% of the pairs. When we consider assignment, biological science faculty are least likely to assign to a firm and most likely to assign to a university. Only $14.2 \%$ of the biological science assignments are to for-profit firms whereas the percentage for the other fields is around 30\%. The percentage assigned to firms by biological science faculty is statistically significantly smaller (1\% level) then those for the other fields.

What is not shown in the table is the fact that firm assignment by engineering faculty has grown steadily over the period of our sample from about $25 \%$ of patents in the earliest years to over $35 \%$ of patents in the last years. Firm assignment by physical science faculty was fairly constant at about $25 \%$ to $30 \%$ but it jumped in the last years to over $35 \%$. There is little variation in firm assignment by biological science faculty over the sample period.

(Insert Table 3 about here)

Assignment patterns based on whether the university is public or private is found in Table 3. A patent from a public university is more likely to be assigned to a firm. Of the 6465 patent/inventor pairs, $62.9 \%$ are public university pairs and $25.5 \%$ of these are assigned only to firms. Firm assignments by pri-

\footnotetext{
${ }^{8}$ The fall off in applications in 1998 \& 1999 and again in 2003 follows from the fact that the NBER patent data ends with patents granted in 1999 and we added patents granted in 2004 to get a distribution across the period.
} 
vate university pairs are $22.1 \%$. These percentages are statistically significantly different at a $1 \%$ level. The corresponding figure for patents assigned to universities is $62.6 \%$ for the public universities and $67.3 \%$ for the private universities. What Table 3 does not show is the change over time in assignment patterns depending on whether the university is public or private. For the private universities the percentage assigned to universities has fallen from roughly $70 \%$ in the early years to around $62 \%$ in the later years. Firm assignment has risen from less than $20 \%$ to almost $30 \%$. University assignment for public universities has fallen from roughly $65 \%$ to $60 \%$ and firm assignment has risen from roughly $22 \%$ to $29 \%$. Private and public universities appear to be converging.

In Table 4 we give the number of patent/inventor pairs by university and their assignment distribution for universities with at least 40 patents in our sample. Universities are ordered according to the number of patent/inventor pairs. The use of patent/inventor pairs rather than patents involves some multiple counting of patents since it is common to have several faculty inventors for the same patent.

(Insert Table 4 about here)

Thirty-seven of the universities have 50 or fewer patents/inventor pairs and only twenty-three have 100 or more pairs. MIT has the largest number (315) of patent/inventor pairs followed by Wisconsin with 232, Stanford with 223, UC San Diego at 216 and rounding out those with over 200 is UC Berkeley with 207. There is substantial variation across universities in assignments. For the universities in Table 4 the percentage assigned to universities varies from a low of 25\% (Arizona with 68 patent/inventor pairs) to a high of $87.8 \%$ (Columbia with 74 pairs). Assignment solely to firms varies from a low of $1.5 \%$ (Vanderbilt with 68 pairs) to a high of $52.6 \%$ (Colorado with 97 pairs).

Of the 5811 patents in our sample 1513 are assigned solely to firms and 241 are assigned both to firms and universities. Since start-up activity is common at research universities we searched for whether the faculty member was a "principal” in the sense that she is linked to the firm as a founder, a senior executive, a member of the scientific advisory board or as a member of the board of directors. ${ }^{9}$ Faculty inventors are principals in the assignee firms for 488 (32.3\%) of the patents assigned solely to firms and 57 (24\%) of the patents that were assigned both to firms and universities. That is, faculty inventors are principals in the assignee firms for $9.4 \%$ of all patents in the sample. This is a lower bound since it is likely that the search for links failed to uncover all links. If we combine these patents with the 327 unassigned patents, then our sample suggests that, as a lower bound, faculty have a direct ownership role for about $15 \%$ of all patents for which they are inventors. Hereafter we refer to the firms in which we have found that the inventor is a principal as a "linked" firm. As noted, these are start-up firms. We refer to the re-

\footnotetext{
${ }^{9}$ For a number of patent/inventor pairs the inventor is listed as having several of these functions. In such a case we consider that there is only a single link between inventor and firm.
} 
maining firms as "established" to differentiate them from start-ups although we caution that some of the firms labeled as established may be start-ups for which we could not find a link.

It is likely that many of the unassigned patents are being used in firms in which the inventor is a principal. We did a search of whether the inventor for an unassigned patent had ever founded a company, been a senior executive of a company or had been a member of the scientific advisory board (or board of directors) of a company. Note that this, unlike the first search, does not link the patent to a company since the patent does not have an assignee. We found that $26.4 \%$ of the unassigned patents were associated with inventors who could be linked to a company. Again, this is a lower bound.

\section{Econometric Model}

In this section logit and multinomial logit models are used to explore the relationship between assignment and characteristics of patents, inventors and the inventor's universities. Our interest is in assignment by type of organization (university, firm, unassigned) so that the patents assigned jointly to a university and to a firm are also deleted from the sample. Finally, we drop the few patents with the federal government as an assignee. These are generally defense-related patents (government assignees are usually sections of the Department of Defense).

The econometric models are used to determine partial correlations between the probability of assignment to a particular type of organization and a set of patent characteristics. In specifying these models we are not implying a causal relationship between patent characteristics and assignment, but rather causality between research activities and assignment and between research and patent characteristics. As discussed in Section 2, where the research is conducted determines legitimate assignment. Since university research tends to be more basic or fundamental than industry research, we expect patents based on research in university labs to be more basic or fundamental than those that result from consulting in firm labs. Thus if firm-assigned patents are more incremental than university-assigned patents, we infer that they are the result of consulting. If firm-assigned patents are similar to or more fundamental than university-assigned patents, the inference is that they may have emanated from university labs. We rely on these inferences since it is the patents along with their assignment and other characteristics that we observe rather than the research activity itself.

\subsection{Independent Variables}

We include four measures of the originality and/or importance of patents from the NBER Patent Database (Hall et al., 2001). Two of the measures are backward looking and attempt to capture basicness of the research. The first is the log of the number of backward citations to prior patents (LN_CITES_MADE) contained in the focal patent. The larger the number of backward citations the lar- 
ger is the existing body of related work, so that we would expect patents with more backward citations to be more incremental. The second backward looking measure is the Trajtenberg et al. (1997) measure of patent originality (ORIGINAL). ORIGINAL is based on a Herfindahl index that reflects the dispersion of citations made by the patent across patent classes. The measure is

$$
\text { Original }_{i}=1-\sum_{j}^{n_{j}} s_{i j}^{2}
$$

where $s_{i j}$ is the percentage of citations made by patent $i$ that belong to patent class $j$ where there are $n_{j}$ patent technology classes. The originality score is higher the wider the range of classes to which the patent makes citations. A score of 0 indicates that all citations to prior art are in a single patent class and scores close to one indicate citations to many classes. A patent is considered more original if it cites prior art from many rather than few technology classes.

The other two patent variables we include are measures of the patent's importance. We include the log of the total number of claims (LN_CLAIMS) since we expect more important patents to have more claims. The log of the number of forward citations received by the patent by October 2006 (LN_FOR_CITES) is included to reflect importance in the sense that the patent has been considered prior art by either subsequent inventors or patent examiners. ${ }^{10}$ The latter measure is subject to error from truncation. For example, the average patent granted in 1995 has 17.6 forward citations, but the average patent granted in 1999 has only 9.5 citations (these are significantly different at the $1 \%$ level). For this reason we caution against placing a great deal of weight on forward citations as a measure of importance even though we do include year fixed effects which should serve to mitigate the error. Finally, including both LN_CITES_MADE and LN_FOR_CITES controls for differences in citation propensities across technological fields.

Clearly, there are flaws in these measures (Sampat, 2004). For example, a patent that has only one citation (hence less dependent on prior art) will have an originality score of zero which suggests that it is not very original. In addition, the number of claims in the patent may simply reflect better patent attorneys. The NBER Patent Database only includes patents granted by 1999 so that the regressions necessarily exclude the subset of our patents that were granted in 2004.

The regressions also include information on the inventor and her department from the National Research Council's survey of Ph.D. granting departments (NRC, 1995). Faculty are divided into three major program areas: physical sciences, engineering and biological sciences. We use indicator variables for physical sciences and engineering (PHY_SCI $=1$ if the department is in the physical sciences and ENG $=1$ for engineering faculty). Just under $4 \%$ of the patent/inventor pairs have faculty from different

\footnotetext{
${ }^{10}$ Since the NBER patent data end in 1999, we updated the forward citations to October 2006.
} 
areas (about 19\% of all patent/inventor pairs have multiple identified faculty), and this creates a problem in the assignment of major program area to a patent. We approach this in the following way. We constructed an indicator variable to indicate whether the patent has more than one identified faculty inventor (CO_INVENT=1 if the patent has several faculty inventors). ${ }^{11}$ Then we randomly dropped all but one coinventor; thus assignment is considered at the unique patent level. As a robustness check we added another indicator variable equal to one when the patent had several faculty inventors from different major program areas and we included all inventor pairs, not just the unique patents. We also estimated models with and without the CO_INVENT variable. Results change very little from model to model so we report only the regressions that use patent level data based on one randomly selected inventor and without the CO_INVENT variable.

We include a measure of the academic quality of the inventor's department (DEPT_QUAL) where higher numbers indicate higher quality academic departments. The measure is from the NRC. In cases where an inventor is listed in several departments a weighted average of quality is used where the weights are the number of faculty in each department. The NRC database includes the rank of the faculty member in 1993, the year the NRC collected the data. We create an indicator variable for faculty who are tenured in 1993 (TENURE_93 = 1 if faculty is a full or associate professor in 1993). This is a crude measure of academic career profile in that someone tenured in 1993 is further along in her career at any year in our sample than someone not tenured in 1993.

The other university regressors include an indicator variable for public/private status (PUBLIC = 1 if the university is public) as well as an indicator for urban/rural university location (URBAN =1). Given the widespread expectation that research in public universities should benefit their local and state economies, we expect faculty in public universities to be more likely to consult and therefore more likely to assign patents to firms. Faculty in universities located in urban areas may well have greater opportunity for local consulting. In addition, access to venture capital is generally regarded to be better in urban areas hence firm start-up activity may be enhanced. For these reasons we expect faculty in urban areas to be more likely to assign to firms. We include the percentage of licensing revenue shared with the inventor (INVENT_SHARE). ${ }^{12}$ This varies across our sample from $20 \%$ to $100 \%$ with a mean of $37.8 \% .^{13}$

\footnotetext{
${ }^{11}$ We are only measuring whether more than one of the faculty in the NRC listing is an inventor. We do not rule out the possibility that there are other university personnel who are co-inventors.

${ }^{12}$ We also collected share of licensing revenues that accrue to the inventor's department however this was not significant in any of our models so we dropped it from the reported analysis.

${ }^{13}$ Several universities have a sliding scale for sharing of licensing proceeds; in such cases we used the share for income that falls between $\$ 25 \mathrm{k}$ and $\$ 50 \mathrm{k}$ as the measure since this is close to the average income across all active licenses. The University of Iowa provides the inventor $100 \%$ of net proceeds for the first $\$ 100 \mathrm{k}$ so it is therefore loaded at $100 \%$ in our data. We also tested minimum university license shares and shares at $\$ 1,000,000$ payout with all results consistent with our results reported here.
} 
After dropping observations with missing data we are left with 4108 observations. Summary statistics for these observations are in Table 5.

(Insert Table 5 about here)

\subsection{Bivariate Logit Model}

We first consider a logit regression model of whether the patent is assigned to a university (coded as a 1) or not assigned to a university (coded as a zero) as a function of patent, inventor, and university characteristics. Patents assigned to both firms and universities or to the federal government are excluded from the analysis so that those patents not assigned to a university either are unassigned or they are assigned to firms. In addition to the regressors discussed above, some of the regressions include year, university and technology fixed effects. The technology categories are from the NBER patent database.

Results in terms of odds ratios are in Table $6 .{ }^{14}$ Ratios greater than one imply that an increase in the regressor leads to a higher probability of assignment to a university with the opposite for odds ratios less than one. In each regression we have included year fixed effects and have included or excluded the technology and university fixed effects. When university fixed effects are included the regressors PUBLIC, URBAN and INVENT_SHARE are redundant since they vary only across universities. The inclusion of technology fixed effects is expected to capture much of the effects of the field indicator variables (ENG and PHY_SCI). In the top panel of the Table (regressions A and B) we have included the university fixed effects. In regression A (B) the technology fixed effects are included (excluded). In the second panel of Table 6 the university fixed effects are excluded and the technology effects are included in regression $\mathrm{C}$ and excluded from regression D. Excluding year effects has very little effect on the results so, for the sake of brevity, those results are not presented.

(Insert Table 6 about here)

The most salient variables for making inferences as to whether assignment outside the university is illicit are the four patent characteristic regressors LN_CLAIMS, LN_CITES_MADE, LN_FOR_CITES and ORIGINAL. As we argued in Section 2, if outside assignment results from consulting, then more basic or important patents should have a higher likelihood of university assignment. Conversely, if research emanating from university labs is illicitly assigned to firms, one would expect either no relationship to patent characteristics or more basic or important patents assigned outside. ORIGINAL and

LN_CITES_MADE are always significant at a $1 \%$ level and consistent with outside assignment reflecting consulting as was suggested in our interviews. Recall the larger the number of backward citations, the larger is the existing related work and therefore the more incremental the patent. Thus the LN_CITES_MADE coefficient below one indicates more incremental patents are not assigned to the uni-

\footnotetext{
${ }^{14}$ An odds ratio gives the effect of a unit change in a right hand side variable on the ratio of the probability of an assignment to a university divided by one minus that probability.
} 
versity. A higher value on ORIGINAL indicates more fundamental work thus a coefficient above one also indicates more incremental patents are not assigned to the university.

The other two patent variables are less clear. LN_CLAIMS (the number of claims) is never significant. When technology fixed effects are present in the regression LN_FOR_CITES (forward citations or citations to the patent) is not significant. It is likely that significance for this variable when technology effects are absent is due to differences in forward citations across technology categories and a difference in the rate of firm assignment by technology class. That is, the results suggest that the technology classes that have the most forward citations are likely to be the classes that have the greatest frequency of assignment to firms.

Regressions C and D of Table 6 include INVENT_SHARE. The higher the inventor share of income the more likely the patent will be assigned to the university. All else equal, high inventor shares provide an incentive for faculty to disclose inventions to the TTO, so this result may simply reflect faculty responding to this incentive. In addition, it may be the case that, as suggested in Jensen et al. (2007), faculty in high share universities may spend less time trying to augment their income by consulting. Both of these effects would tend to increase the likelihood of assignment to the university.

When technology fixed effects are included (regressions A and C) there is not a significant difference between assignment of engineers (ENG) and biological scientists and between physical scientists (PHY_SCI) and biological sciences. We tested whether ENG and PHY_SCI are significantly different and found that there is a significantly higher probability (1\% level) that engineers assign to the university. However, when we exclude the technology fixed effects both physical scientists and engineers are less likely to assign to the university than are biological scientists and this is significant at the $1 \%$ level. Tests of differences between ENG and PHY_SCI reveal that they are not significantly.

Department quality is significant only in regression C but the level of significance is only $10 \%$. There is also weak evidence that older faculty (crudely measured as having tenure in 1993) are more likely to assign to the university and that faculty in urban universities are more likely to assign outside the university. As expected, public university faculty are more likely to assign to a firm than the university.

As an additional robustness check, these models were estimated with a more restrictive dependent variable; the unassigned patents were deleted from consideration and the models run on those patents solely assigned to universities and those solely assigned to firms. The results are unchanged.

\subsection{Multinomial Comparison}


Thus far, we have compared university patents with all other patents. In this section, we disaggregate the other patents and use a multinomial logit model of assignment. The categories and the shorthand notation for each are

1. UNIV - The patent is assigned to one or more universities

2. UNASSIGN - The patent is unassigned and therefore owned by the inventor(s)

3. LINK - The patent is assigned to a firm in which a link could be found between the firm and the inventor. That is, the inventor is a principal in the firm.

4. ESTBL - The patent is assigned to a firm and it could not be determined that the inventor is a principal in the firm. The firm is an established firm rather than a start-up.

The "link" category consists of all patents for which we were able to identify a faculty inventor as a principal in the assignee firm (that is, she either is a founder, an executive or a member of a board). Since this search is unlikely to have uncovered all links, group 4 may well include patents that properly belong to group 3. This misclassification is most likely to occur for young firms since young firms are more likely to be start-ups in which faculty members are principals. Thus we also separated the patents in group 4 into those assigned to old, established firms and those assigned to young firms. We considered any firm established before 1980 as old, so that an old firm is one that is 10 years old or older at the time of the patent application. In both logit and multinomial logit regressions we find the only difference in these two groups is that faculty from engineering and the physical sciences and faculty in higher quality departments are more likely to assign to an old rather than a young firm. Thus we drop further consideration of firm age. Unassigned patents might be argued to properly belong with the patents in group 3, but there are important differences between the patents in groups 2 and 3 so that we will consider unassigned patents as a separate category.

The results are in Table 7. The coefficients are presented as relative risk ratios (RRR). ${ }^{15}$ If the RRR of an independent variable is greater than one (smaller than one), then an increase in the independent variable is associated with an increase (decrease) in the risk of the numerator type of assignment relative to the denominator type of assignment. For example, consider the results in panel A of the table which shows the comparison of unassigned patents with patents assigned to a university (UNASSIGN/UNIV). If DEPT_QUAL increases by a score of one the risk of UNASSIGN relative to UNIV rises by $36.4 \%$ so that faculty in higher quality departments are more likely to have unassigned patents. If the faculty member is a physical scientist (PHY_SCI $=1$ ), then the risk of UNASSIGN relative to UNIV falls by $32.1 \%$ so that physical scientists are more likely to assign to their university in comparison to the omitted category biological scientists.

\section{(Insert Table 7 about here)}

\footnotetext{
${ }^{15}$ A relative risk ratio is very similar to an odds ratio.
} 
Panels A, B and C are comparisons of patents assigned to universities (UNIV) versus those that are unassigned (UNASSIGN), universities versus patents assigned to firms where there is link between the firm and the inventor (LINK) and universities versus patents assigned to firms where we could not find a link to the inventor (ESTBL). Interestingly, among these three comparisons the greatest difference between university and non-university assignment is that for LINK versus UNIV. With the exception of PHY_SCI all coefficients in panel B are significant at least at a 10\% level and the magnitudes of the relative risk ratios are generally larger than they are for the other two comparisons. In other words, the patents that are most different from university assigned patents are those patents assigned to start-up firms. Panels $\mathrm{D}, \mathrm{E}$ and $\mathrm{F}$ are comparisons of patents not assigned to universities.

Only models with technology class fixed effects are considered to allow for the greatest number of regressors. We also consider year fixed effects. Results with university fixed effects are very similar to those reported in Table 7 so for the sake of brevity we omit the detailed results.

\subsubsection{Patent Characteristics}

As before, the variables most pertinent for examining illicit assignment are the patent characteristic variables LN_CLAIMS, LN_CITES_MADE, LN_FOR_CITES and ORIGINAL in the comparisons that involve university assignments. These are in panels A, B and C. There is evidence that the broader the patent, in terms of more claims, the more likely it will be assigned to the university versus a firm with an inventor link or unassigned, but the number of claims is not significant in the ESTBL versus UNIV assignment (panel C). Before we continue with panels A, B and C note that LN_CLAIMS is significant in the comparisons ESTBL/LINK (panel E) and UNASSIGN/ESTBL (panel F), and, in both, more claims imply a higher likelihood of ESTBL assignment. Since we would expect universities and firms with no inventor links (which tend to be large firms) to have more resources for patent applications, this result may reflect access to better legal advice in patenting.

More forward cites are positively related to assignment to LINK firms versus UNIV while the opposite holds for ESTBL versus UNIV assignment. LINK firm patents also have more citations than either ESTBL or UNASSIGN. As we cautioned earlier, care must be taken in attributing much to our measure of forward citations because of truncation error. LN_CITES_MADE is significant for each of the three comparisons involving universities with more citations having a higher likelihood of assignment outside the university. The more original the patent the more likely it will be assigned to UNIV than to LINK or ESTBL. ORIGINAL is not significant in the UNASSIGN/UNIV comparison. Taken together, the results are similar to those obtained in the bivariate logit model: more basic patents are more likely to be assigned to the university regardless of whether the firm is or is not linked to the inventor.

To the extent that the backward looking measures reflect how basic the underlying research was, the backward looking measures suggest that the research behind patents assigned to universities was more 
fundamental than the research behind those assigned elsewhere. By implication, therefore, we argue that the backward looking measures do not support the case that assignment outside the university is nefarious. By contrast the results for forward cites are mixed. When the comparison is between non-linked firms and universities the results suggest legitimate assignment. However, for linked firms versus universities the more important the patent (in terms of forward cites) the more likely the patent will be assigned to a linked firm. The lack of significance for LN_CLAIMS (except for the $10 \%$ significance in panel B) does not support the legitimate assignment case.

Results are somewhat mixed in the comparison between UNASSIGN and UNIV (panel A). Unassigned patents are more incremental than university assigned patents and they tend to be less broad in that they have fewer claims. However, there appears to be no difference in the originality of the patents. Earlier we noted that unassigned patents include some that have been turned back to the inventor by the university, hence the weak results are not a surprise.

\subsubsection{Inventor and University Characteristics}

As shown in panels B and C, a higher inventor share increases the likelihood of university assignment as compared with assignment to a firm in which the inventor is a principal (LINK) but it has no effect on assignment to established firms (ESTBL) versus the university. INVENT_SHARE is significant in ESTBL/LINK and UNASSIGN/LINK and in both cases higher inventor share decreases the likelihood of assignment to a linked firm. Thus all of the comparisons involving linked firms suggest that faculty in high share universities are less likely to assign patents to firms in which they are principals. As in the bivariate model, the results on INVENT_SHARE may simply reflect faculty in low share universities being less willing to disclose, but they may also reflect increased efforts to earn income outside the university. The lack of significance in the comparison of ESTBL/UNIV suggests that to the extent this occurs, it is not through consulting with established firms but through work with firms in which the inventor is a

principal. Note, however, that we cannot say whether the latter effect involves legitimate consulting with startups or illegally taking university generated inventions outside of the university.

Despite the fact that technology fixed effects are included in the regressions reported in Table 7, there are still some significant effects by major program area. Physical scientists and engineers tend to be more similar to each other than to biological scientists as each shows similar assignment trend across the panels. Though the coefficients are not always significant, they are more likely than biological scientists to assign to ESTBL than to LINK, UNASSIGN or UNIV. They are also more likely than biological scientists to assign to UNIV than to LINK or UNASSIGN.

Faculty in public universities are more likely than those in private universities to assign to LINK rather than UNIV, ESTBL or UNASSIGN. That is, public university inventors are more likely to be involved with start-ups. Public university faculty are also more likely to assign to ESTBL than to UNIV. 
Faculty in urban universities are more likely to assign to LINK than UNIV or ESTBL. Urban faculty are also more likely be inventors on UNASSIGN patents than UNIV or ESTBL. Urban university inventors are more likely to be involved in start-ups.

\section{Conclusion}

University-industry knowledge flows occur through a wide variety of mechanisms, some of which are formal and easily tracked - such as publications, patents, licenses - and others that are harder to track such as faculty consulting and the movement of personnel (Mowery et al., 2004). Because consulting is less visible, it is one of the less researched aspects of university to industry technology transfer. This is an important gap in our understanding since the research that has been done suggests industrial R\&D personnel view consulting as important and, in fact, more important than patents or licenses (Cohen et al., 1998). ${ }^{16}$ In our attempt to better understand the role of university faculty in university-industry technology transfer, we have shown that patents themselves can provide some insights (albeit indirect) into this understudied mechanism.

In contrast to prior work that identified faculty patents by searching for patents assigned to universities, our approach has been to find faculty patents by focusing on the inventors. This allows us to find faculty patents that are not assigned to universities (or other non-profits). With this approach we find that a substantial fraction of faculty patents (around 26\%) are assigned solely to firms. According to university and industry personnel, this likely is the result of consulting. However, a third of the firm assignments are to firms in which we can identify the faculty inventor as a principal. In this case, it is possible that the intellectual property in these patents includes not only the IP developed in the course of consultation, but also IP that is rightfully (according to employment contracts) the property of the university.

We estimated a series of probability models of assignment as a function of patent and university characteristics as well as inventor field. In both our logit and multinomial logit models we find that patents assigned to the university tend to be more basic than those assigned outside, suggesting that outside assignment results from research conducted in firm labs. We also find faculty in the physical sciences and engineering are much more likely to assign to established firms than those in biological sciences. Faculty at urban universities are much more likely to assign their patents to a firm in which they are a principal than faculty from a rural area, which as noted, could be an effect of better access to venture capital in urban areas.

\footnotetext{
${ }^{16}$ In the Carnegie Mellon Survey conducted in the early 1990s, 31 percent of respondents listed consulting as "very important" for industrial R\&D, while only 17 percent said the same for patents and 9 percent said the same for licenses.
} 
From a policy perspective, perhaps the most interesting university factor we consider is the share of revenue from licensing that accrues to the inventor when inventions are assigned to and licensed by the university. In our regression analysis, a higher inventor share increases the likelihood of university assignment as compared with assignment to a firm in which the inventor is a principal but it has no effect on consulting with established firms versus assignment to the university.

Again, with regard to policy, recent research examining the impact of the 2000 Bayh-Dole type legislation in Denmark expresses concerns that the ability of universities to claim ownership of faculty patents might interfere with healthy university industry collaboration (Valentin and Jensen, 2007). Our results suggest that in the United States, Bayh-Dole may not have interfered with this collaboration. This is not to say, however, that universities asserting invention ownership has not caused frictions in industry relations. As evidenced by recent policy discussions, aggressive university effort to own results of sponsored research has become a controversial issue (see, for example, Thursby and Thursby, 2006)

Finally, we should note the limitations of our analysis. While our results allow us to make inferences about the nature of faculty consulting, they only provide insights on the nature of consulting which results in patents. This research shows, however, that a view of university research which does not account for such faculty work in industrial settings will miss a good deal of the innovative work produced by U.S. university science and engineering faculty members.

\section{Acknowledgements}

The authors gratefully acknowledge research support from the Ewing Marion Kauffman Foundation. Fuller acknowledges support from the Alan and Mildred Peterson Foundation, and M. Thursby acknowledges support from the National Science Foundation. Participants of seminars at University College London, London Business School, the 2006 Technology Transfer Society meeting and 2006 Roundtable on Engineering Entrepreneurship Research at Georgia Institute of Technology provided useful comments. We thank Bhaven Sampat for providing access to his patent database. 


\section{Appendix: Name Ranking and Screening}

Once the university faculty names were paired up with the inventor names and addresses from the patent application, a multi-staged name screening process was developed. The first step in the process was to check the university address with the address provided for the inventor on the patent application. If the university zip code was a distance of more than 50 miles from the inventor address in the patent, the patent was removed from the database. This conservative approach will likely remove some valid pairings; however there is no reason to believe this approach introduces any bias between patents assigned to a university and those not assigned to a university.

Once the zip code distances were established, surname data from the 1990 Census was employed to evaluate the incidence of each name. Over 60,000 surnames and their frequency of occurrence were downloaded from the U.S. Census Bureau. This represents over $88 \%$ of the total surnames in the 1990 Census database. The most commonly used name was "Smith" representing $1.006 \%$ of the Census population. The lower end of our surname dataset contains names representing less than $0.000125 \%$ of the census population.

We then categorized each inventor into one of 6 name match types. We utilized this data to set name matching cutoff points for each type of name match. For example if a name matched completely on first, middle and last name for the university faculty listing and the patent listing it was a 'type 1' name match. Given that this match type is the most rigorous we set the most permissible threshold for this type. One could ask why we did not accept all of the matches for this name type however we chose a conservative approach to limit a name such as "James Robert Smith" from our dataset due to the relatively high occurrence of each of those three names. Our optimal threshold (0.8\%) eliminates any Smith and Johnson surnames from the dataset.

The next name types are a full match for two names and also a match of initials for the other name (either first or middle). Our optimal threshold (0.28\%) eliminates the top 13 possible surnames from this name type. Next we considered those names with matching first and last and a missing middle name or initial. We set the threshold $(0.1 \%)$ for this category to eliminate the top 75 surnames. Therefore a name such as "John Sanders" in this name type is deleted from the dataset. The final two categories deal with only initials matching in the first and/or middle names. In the case where both first and middle initials match, our threshold (0.03\%) eliminates 378 possible surnames so that "M.B. Walton" would be deleted from our dataset. Finally when only one initial was a match, we set a threshold (0.0005\%) to eliminate over 18,800 surnames so that "R. Acres" would be deleted. These thresholds yielded about $90 \%$ of our database to continue on for further analysis.

Next we sought a secondary source to verify the university affiliation for each remaining name. Here we focused on patents that were not assigned to a university. We reasoned the likelihood of a faculty match is quite high if the inventor assigns the patent to a university. We utilized the National Faculty Directory (NFD) from years just prior and after the patent application date. Realizing the NFD is oriented towards textbook publishers and may not have some research oriented faculty, we did further school and internet searches of faculty not successfully identified through the NFD. Quite often we were able to find faculty through the university web-sites sometimes even if they are currently emeritus status. In the case where we were not able to explicitly identify the name match with the focal school, the entry was eliminated from our dataset. 


\section{References}

1995, National Research Council. In: M. Goldberger, B. Maher and P. Flattau (Eds.), Research Doctorate Programs in the United States. National Academy Press, Washington, D.C.

Audretsch, D. B., Aldridge, T., Oettl, A., 2006, The knowledge filter and economic growth: The role of scientist entrepreneurship. Ewing Marion Kauffman Foundation.

Cohen, W. M., Florida, R., Randazzese, L., Walsh, John, 1998, Industry and the Academy: Uneasy partners in the cause of technological advance. in R. Noll, ed., Challenges to the Research University. Washington, D.C: Brookings Institution.

Crespi, G. A., Geuna, A., Verspagen, B., 2006, University IPRs and knowledge transfer. Is the IPR ownership model more efficient? , 2006 Roundtable Engineering Entrepreneurship Research, Georgia Institute of Technology, pp. 27.

Di Gregorio, D., Shane, S. 2003. Why Do Some Universities Generate More Start-ups Than Others? Research Policy, 32, 209-227.

Fuller, A. W., Thursby, M. C., 2007, Cooperative vs. Competititive strategy: Alliance, License vs. Venture, Advances in the study of entrepreneurship, innovation and economic growth. Elsevier.

Geuna, A., Nesta, L. J.J., 2006. University patenting and its effects on academic research: the emerging European evidence. Research Policy, 35, 790-807.

Hall, B. H., Jaffe, A. B., Trajtenberg, M., 2001. The NBER patent citations data file: Lessons, insights and Methodological Tools. NBER working paper series.

Henderson, R., Jaffe, A. B., Trajtenberg, M., 1998. Universities as a source of commercial technology: A detailed analysis of university patenting 1965- 1988. The Review of Economics and Statistics, 119-127.

Jaffe, A. B., 1989. Real effects of academic research. American Economic Review, 79(5), 957-970.

Jaffe, A. B., Trajtenberg, M., Henderson, R., 1993. Geographic localization of knowledge spillovers as evidenced by patent citations. Quarterly Journal of Economics, August 1993, 577-598.

Jensen, R., Thursby, J. G, Thursby, M. C., 2006, In or Out: Faculty research and consulting, Roundtable on Engineering Entrepreneurship Research Georgia Institute of Technology, pp. 20.

Jensen, R., Thursby, M. C., 2001. Proofs and Prototypes for Sale: The licensing of university inventions. The American Economic Review, 91(1), 240-259

Lach, S., Schankerman, M., 2004. Royalty sharing and technology licensing in universities. Journal of the European Economic Association, 2(3), 252-264.

Macho-Stadler, I., Perez-Castrillo, J. D., Veugelers, R., 2005, Licensing of University Inventions: the role of a technology transfer office. BBVA, pp. 49.

Mansfield, E., 1995. Academic research underlying industrial innovations: sources, characteristics, and financing. The Review of Economics and Statistics, 77, 55-65. 
Markman, G. D., Gianiodis, P. T., Phan, P. H., 2006, Full-Time faculty or part-time entrepreneurs?, Technology Transfer Society Meeting 2006, Atlanta, GA, pp. 29.

Mowery, D. C., Nelson, R. R., Sampat, B. N., Ziedonis, A. A., 2001. The growth of patenting and licensing by U.S. universities: An assessment of the effects of the Bayh-Dole act of 1980. Research Policy, 30, 99-119.

Mowery, D. C., Nelson, R. R., Sampat, B. N., Ziedonis, A. A. 2004. Ivory Tower and Industrial Innovation: U.S. University-Industry Technology Transfer Before and After the Bayh-Dole Act. Stanford: Stanford University Press.

Rothaermal, F., M. Thursby. 2005. Incubator firm failure or graduation? The role of university linkages. Research Policy, 34, 1079-1090.

Sampat, B.N., 2004. Examining patent examination: An analysis of examiner and applicant generated prior art, mimeo.

Saragossi, S., van Pottelsberghe de la Potterie, B., 2003. What patent data reveal about universitities: the case of Belgium. Journal of Technology Transfer, 28, 47-51.

Thursby, J. G., Jensen, R., Thursby, M. C., 2001. Objectives, characteristics and outcomes of university licensing: A survey of major U.S. universities. Journal of Technology Transfer, 26, 59-72.

Thursby, J. G., Thursby, M. C., 2004. Are Faculty Critical? Their role in university-industry licensing. Contemporary Economic Policy, 22(2), 162-178.

Thursby, J. G., Thursby, M. C., 2005. Faculty patent activity and assignment patterns, Report to the Kauffman foundation, Kansas City, MO.

Thursby, M. C., Thursby, J. G., 2006. Where is the new science in corporate R\&D? Science, 314 (Dec. 8, 2006), 1547-1547.

Trajtenberg, M., Jaffe, A. B., Henderson, R., 1997. University versus Corporate Patents: A window on the basicness of invention. Economics of Innovation \& New Technology, 5(1), 19-50.

Trajtenberg, M., Shiff, G., Melamed, R., 2006, The 'Names Game": Harnessing inventors' patent data for economic research, National Bureau of Economic Research, Cambridge, MA, pp. 75.

Valentin, F., Jensen, R. L., 2007, Effects on academia-Industry collaboration of extending university property rights, Journal of Technology Transfer, 32(3), 251-276.

Zucker, L. G., Darby, M. R., 2006, Movement of star scientists and engineers and high-tech firm entry. National Bureau of Economic Research, pp. 37. 
Table 1. Patent Applications and Assignment

\begin{tabular}{ccccccc} 
& Total Patents & University & Firm & Unassigned & Univ \& Firm & US Govt \\
\cline { 2 - 6 } 1993 \& earlier & 1384 & 64.7 & 23.3 & 6.4 & 3.2 & 2.4 \\
1994 & 491 & 65.6 & 20.6 & 5.9 & 6.7 & 1.2 \\
1995 & 1017 & 62.5 & 25.2 & 5.8 & 4.5 & 2.0 \\
1996 & 573 & 63.5 & 24.4 & 7.0 & 3.3 & 1.7 \\
1997 & 721 & 62.8 & 27.0 & 4.3 & 4.2 & 1.7 \\
1998 & 270 & 56.7 & 31.1 & 7.0 & 4.1 & 1.1 \\
1999 & 119 & 64.7 & 23.5 & 5.0 & 5.0 & 1.7 \\
2000 & 278 & 59.0 & 29.9 & 4.0 & 5.8 & 1.4 \\
2001 & 454 & 62.8 & 28.2 & 2.4 & 5.3 & 1.3 \\
2002 & 370 & 58.1 & 33.0 & 6.2 & 1.9 & 0.8 \\
2003 \& 2004 & 134 & 47.0 & 39.6 & 7.5 & 3.7 & 2.2 \\
Total & 5811 & 62.4 & 26.0 & 5.6 & 4.1 & 1.8
\end{tabular}

Table 2. Major Program Area by Patent/Inventor Pair

\begin{tabular}{lcccccc} 
& Total Pairs & University & Firm & Unassigned & Univ \& Firm & US Govt \\
\cline { 2 - 7 } Biological Sciences & 2308 & 74.2 & 14.2 & 4.1 & 6.0 & 1.5 \\
Engineering & 2514 & 58.0 & 30.5 & 6.7 & 2.8 & 2.0 \\
Physical Sciences & 1643 & 60.2 & 28.7 & 4.9 & 4.3 & 1.9 \\
All Fields & 6465 & 64.3 & 24.2 & 5.3 & 4.3 & 1.8
\end{tabular}

Table 3. Public/Private Universities and Assignment by Patent/Inventor Pair

\begin{tabular}{lcccccc} 
& Total Pairs & University & Firm & Unassigned & Univ \& Firm & US Govt \\
\cline { 2 - 6 } Private & 2397 & 67.3 & 22.1 & 5.6 & 3.8 & 1.3 \\
Public & 4068 & 62.6 & 25.5 & 5.2 & 4.6 & 2.1 \\
Total & 6465 & 64.3 & 24.2 & 5.3 & 4.3 & 1.8
\end{tabular}

Table 4: University and Assignment by Patent/Inventor Pair

\begin{tabular}{lcrrrrr} 
University & Total Pairs & University & \multicolumn{1}{c}{ Firm } & Unassigned & Univ \& Firm & US Govt \\
\cline { 2 - 6 } MIT & 315 & $64.4 \%$ & $21.3 \%$ & $10.5 \%$ & $2.9 \%$ & $0.0 \%$ \\
Wisconsin & 232 & $65.5 \%$ & $28.0 \%$ & $3.9 \%$ & $2.6 \%$ & $0.0 \%$ \\
Stanford & 223 & $46.6 \%$ & $49.3 \%$ & $2.2 \%$ & $0.9 \%$ & $0.9 \%$ \\
UC-San Diego & 216 & $61.1 \%$ & $31.0 \%$ & $4.6 \%$ & $2.3 \%$ & $0.9 \%$ \\
UC-Berkeley & 207 & $55.1 \%$ & $36.2 \%$ & $4.8 \%$ & $2.4 \%$ & $1.4 \%$ \\
Michigan & 183 & $74.3 \%$ & $16.9 \%$ & $4.4 \%$ & $2.2 \%$ & $2.2 \%$ \\
Pennsylvania & 180 & $80.6 \%$ & $12.2 \%$ & $3.9 \%$ & $1.7 \%$ & $1.1 \%$ \\
Utah & 153 & $54.9 \%$ & $35.9 \%$ & $3.3 \%$ & $5.2 \%$ & $0.7 \%$ \\
UC-San Francisco & 143 & $53.8 \%$ & $28.7 \%$ & $8.4 \%$ & $9.1 \%$ & $0.0 \%$ \\
Univ of Washington & 139 & $64.0 \%$ & $21.6 \%$ & $7.2 \%$ & $7.2 \%$ & $0.0 \%$ \\
CalTech & 139 & $79.9 \%$ & $13.7 \%$ & $2.2 \%$ & $4.3 \%$ & $0.0 \%$ \\
Cornell & 134 & $63.4 \%$ & $29.1 \%$ & $5.2 \%$ & $0.7 \%$ & $1.5 \%$ \\
Johns Hopkins & 133 & $79.7 \%$ & $9.0 \%$ & $2.3 \%$ & $7.5 \%$ & $1.5 \%$ \\
Texas at Austin & 131 & $47.3 \%$ & $26.0 \%$ & $10.7 \%$ & $14.5 \%$ & $1.5 \%$ \\
Rutgers & 124 & $57.3 \%$ & $29.0 \%$ & $6.5 \%$ & $5.6 \%$ & $1.6 \%$ \\
Florida & 123 & $67.5 \%$ & $21.1 \%$ & $3.3 \%$ & $5.7 \%$ & $2.4 \%$ \\
U of Illinois at UC & 121 & $61.2 \%$ & $27.3 \%$ & $5.8 \%$ & $4.1 \%$ & $1.7 \%$ \\
UC-Los Angeles & 114 & $47.4 \%$ & $42.1 \%$ & $6.1 \%$ & $4.4 \%$ & $0.0 \%$ \\
Harvard & 110 & $56.4 \%$ & $32.7 \%$ & $6.4 \%$ & $1.8 \%$ & $0.9 \%$ \\
Pennsylvania State & 110 & $71.8 \%$ & $20.9 \%$ & $2.7 \%$ & $3.6 \%$ & $0.9 \%$
\end{tabular}




\begin{tabular}{|c|c|c|c|c|c|c|}
\hline Washington & 109 & $69.7 \%$ & $18.3 \%$ & $7.3 \%$ & $3.7 \%$ & $0.9 \%$ \\
\hline Minnesota & 102 & $58.8 \%$ & $29.4 \%$ & $6.9 \%$ & $2.9 \%$ & $2.0 \%$ \\
\hline SUNY-Stony Brook & 102 & $73.5 \%$ & $16.7 \%$ & $5.9 \%$ & $2.9 \%$ & $1.0 \%$ \\
\hline UC-Santa Barbara & 99 & $70.7 \%$ & $22.2 \%$ & $5.1 \%$ & $2.0 \%$ & $0.0 \%$ \\
\hline Pittsburgh & 99 & $80.8 \%$ & $15.2 \%$ & $3.0 \%$ & $1.0 \%$ & $0.0 \%$ \\
\hline Colorado & 97 & $41.2 \%$ & $52.6 \%$ & $6.2 \%$ & $0.0 \%$ & $0.0 \%$ \\
\hline North Carolina State & 97 & $60.8 \%$ & $25.8 \%$ & $1.0 \%$ & $4.1 \%$ & $8.2 \%$ \\
\hline GA Tech & 97 & $76.3 \%$ & $15.5 \%$ & $4.1 \%$ & $1.0 \%$ & $3.1 \%$ \\
\hline Princeton & 93 & $66.7 \%$ & $17.2 \%$ & $7.5 \%$ & $7.5 \%$ & $1.1 \%$ \\
\hline Alabama-Birmingham & 92 & $73.9 \%$ & $8.7 \%$ & $8.7 \%$ & $5.4 \%$ & $3.3 \%$ \\
\hline Northwestern & 90 & $50.0 \%$ & $33.3 \%$ & $8.9 \%$ & $5.6 \%$ & $2.2 \%$ \\
\hline NYU & 86 & $64.0 \%$ & $14.0 \%$ & $10.5 \%$ & $11.6 \%$ & $0.0 \%$ \\
\hline UNC-Chapel Hill & 86 & $65.1 \%$ & $12.8 \%$ & $3.5 \%$ & $12.8 \%$ & $5.8 \%$ \\
\hline Michigan State & 79 & $78.5 \%$ & $17.7 \%$ & $0.0 \%$ & $2.5 \%$ & $1.3 \%$ \\
\hline Ohio State & 76 & $75.0 \%$ & $18.4 \%$ & $0.0 \%$ & $5.3 \%$ & $1.3 \%$ \\
\hline Columbia & 74 & $87.8 \%$ & $9.5 \%$ & $2.7 \%$ & $0.0 \%$ & $0.0 \%$ \\
\hline Duke & 73 & $57.5 \%$ & $26.0 \%$ & $9.6 \%$ & $6.8 \%$ & $0.0 \%$ \\
\hline VPI & 73 & $64.4 \%$ & $13.7 \%$ & $4.1 \%$ & $17.8 \%$ & $0.0 \%$ \\
\hline UC-Davis & 72 & $73.6 \%$ & $13.9 \%$ & $6.9 \%$ & $4.2 \%$ & $1.4 \%$ \\
\hline Carnegie Mellon & 71 & $66.2 \%$ & $31.0 \%$ & $2.8 \%$ & $0.0 \%$ & $0.0 \%$ \\
\hline Arizona & 68 & $25.0 \%$ & $51.5 \%$ & $11.8 \%$ & $7.4 \%$ & $4.4 \%$ \\
\hline Vanderbilt & 68 & $69.1 \%$ & $1.5 \%$ & $5.9 \%$ & $19.1 \%$ & $4.4 \%$ \\
\hline Yale & 63 & $77.8 \%$ & $15.9 \%$ & $1.6 \%$ & $4.8 \%$ & $0.0 \%$ \\
\hline Purdue & 61 & $62.3 \%$ & $24.6 \%$ & $3.3 \%$ & $9.8 \%$ & $0.0 \%$ \\
\hline UC-Irvine & 57 & $71.9 \%$ & $7.0 \%$ & $7.0 \%$ & $8.8 \%$ & $5.3 \%$ \\
\hline Maryland - CP & 54 & $44.4 \%$ & $20.4 \%$ & $9.3 \%$ & $1.9 \%$ & $24.1 \%$ \\
\hline Rochester & 53 & $50.9 \%$ & $45.3 \%$ & $3.8 \%$ & $0.0 \%$ & $0.0 \%$ \\
\hline lowa & 51 & $84.3 \%$ & $3.9 \%$ & $5.9 \%$ & $2.0 \%$ & $3.9 \%$ \\
\hline Connecticut & 50 & $54.0 \%$ & $32.0 \%$ & $2.0 \%$ & $2.0 \%$ & $10.0 \%$ \\
\hline Virginia & 50 & $60.0 \%$ & $20.0 \%$ & $8.0 \%$ & $8.0 \%$ & $4.0 \%$ \\
\hline Southern California & 49 & $63.3 \%$ & $24.5 \%$ & $10.2 \%$ & $2.0 \%$ & $0.0 \%$ \\
\hline Wayne State & 48 & $45.8 \%$ & $37.5 \%$ & $4.2 \%$ & $10.4 \%$ & $2.1 \%$ \\
\hline SUNY-Buffalo & 48 & $66.7 \%$ & $20.8 \%$ & $4.2 \%$ & $2.1 \%$ & $6.3 \%$ \\
\hline Kentucky & 46 & $76.1 \%$ & $19.6 \%$ & $4.3 \%$ & $0.0 \%$ & $0.0 \%$ \\
\hline Texas A\&M & 45 & $71.1 \%$ & $22.2 \%$ & $4.4 \%$ & $2.2 \%$ & $0.0 \%$ \\
\hline Chicago & 42 & $64.3 \%$ & $26.2 \%$ & $4.8 \%$ & $0.0 \%$ & $4.8 \%$ \\
\hline Case Western & 42 & $69.0 \%$ & $14.3 \%$ & $2.4 \%$ & $9.5 \%$ & $4.8 \%$ \\
\hline Emory & 42 & $83.3 \%$ & $7.1 \%$ & $4.8 \%$ & $0.0 \%$ & $4.8 \%$ \\
\hline Illinois at Chicago & 40 & $57.5 \%$ & $32.5 \%$ & $10.0 \%$ & $0.0 \%$ & $0.0 \%$ \\
\hline
\end{tabular}


Table 5. Summary Statistics

\begin{tabular}{lrrrrr} 
& Observations & Mean & St. Error & Min & Max \\
\cline { 2 - 6 } PHY_SCI & 4133 & 0.266 & 0.442 & 0 & 1 \\
ENG & 4133 & 0.383 & 0.486 & 0 & 1 \\
DEPT_QUAL & 4133 & 3.760 & 0.730 & 1.35 & 4.97 \\
TENURE_93 & 4108 & 0.836 & 0.370 & 0 & 1 \\
CLAIMS & 4133 & 19.026 & 16.179 & 1 & 218 \\
CITES_MADE & 4133 & 9.644 & 13.983 & 0 & 356 \\
FOR_CITES & 4133 & 12.907 & 20.133 & 0 & 303 \\
ORIGINAL & 4133 & 0.389 & 0.304 & 0 & 0.93879 \\
PUBLIC & 4133 & 0.625 & 0.484 & 0 & 1 \\
URBAN & 4133 & 0.784 & 0.412 & 0 & 1 \\
INVENT_SHARE & 4133 & 38.007 & 10.426 & 20 & 100
\end{tabular}

Table 6. Bivariate Logit Assignment Results

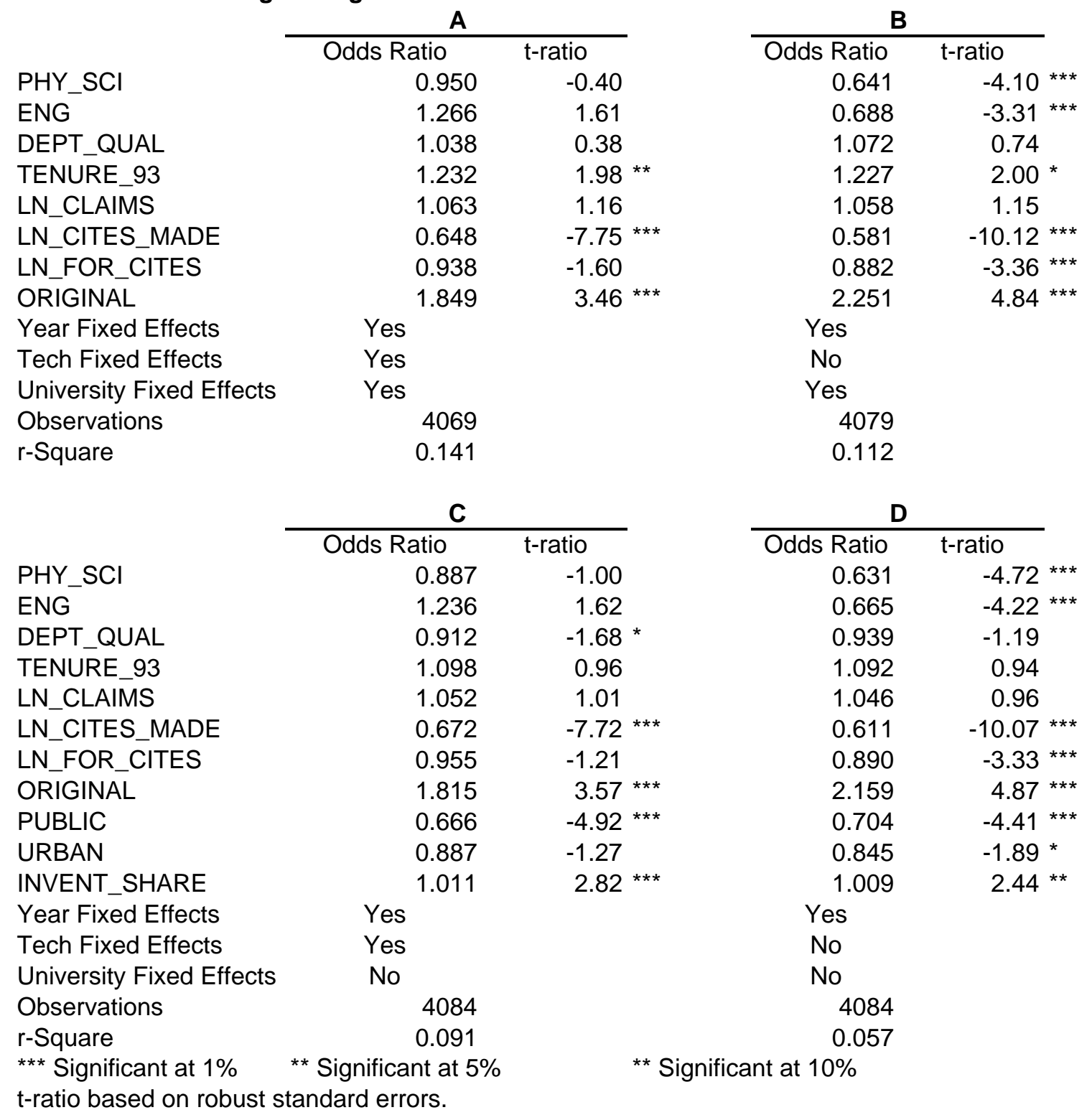


Table 7. Multinomial Logit Assignment Results

\section{A. UNASSIGN/UNIV}

PHY_SCI
ENG
DEPT_QUAL
TENURE_93
LN_CLAIMS
LN_CITES_MADE
LN_FOR_CITES
ORIGINAL
PUBLIC
URBAN
INVENT_SHARE

\begin{tabular}{|c|c|}
\hline RRR & t-ratio \\
\hline 0.679 & -1.56 \\
\hline 0.499 & -2.56 \\
\hline 1.364 & $2.81 * * *$ \\
\hline 0.830 & -0.99 \\
\hline 0.785 & $-2.51 * \star$ \\
\hline 1.226 & $2.07 * *$ \\
\hline 1.091 & 1.15 \\
\hline 0.824 & -0.58 \\
\hline 1.150 & 0.90 \\
\hline 1.755 & $2.60 * *$ \\
\hline 1.005 & 0.65 \\
\hline
\end{tabular}

\section{ESTBL/UNIV}

PHY_SCI
ENG
DEPT_QUAL
TENURE_93
LN_CLAIMS
LN_CITES_MADE
LN_FOR_CITES
ORIGINAL
PUBLIC
URBAN
INVENT_SHARE

\begin{tabular}{cc}
\hline RRR & t-ratio \\
\hline 1.649 & 3.28 \\
1.161 & 0.90 \\
0.960 & -0.63 \\
0.738 & -2.73 \\
1.054 & 0.85 \\
1.512 & $6.48^{* * *}$ \\
0.912 & $-2.03^{* *}$ \\
0.492 & -3.57 \\
1.353 & 2.97 \\
$0.90 *$ \\
0.999 & -0.89 \\
& -0.36
\end{tabular}

\section{E. ESTBL/LINK}

PHY_SC

ENG

DEPT_QUAL

TENURE_93

LN_CLAIMS

LN_CITES_MADE

LN_FOR_CITES

ORIGINAL

PUBLIC

URBAN

INVENT_SHARE

Year Fixed Effects

Tech Fixed Effects

University Fixed Effects

Observations

UNIV

ESTBL

LINK

UNASSIGN

r-Square

*** Significant at 1\% ** Significant at 5\%

t-ratio based on robust standard errors.

\section{B. LINK/UNIV}

\begin{tabular}{|c|c|}
\hline RRR & t-ratio \\
\hline 0.703 & -1.63 \\
\hline 0.558 & 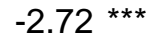 \\
\hline 1.298 & $2.58 * \star \star$ \\
\hline 2.195 & $3.44^{* * *}$ \\
\hline 0.844 & -1.94 * \\
\hline 1.658 & $5.62 * \star \star$ \\
\hline 1.470 & $5.67^{\star * *}$ \\
\hline 0.515 & $-2.15 * \star$ \\
\hline 2.447 & $5.91 * \star \star$ \\
\hline 1.995 & $3.47^{\star \star *}$ \\
\hline 0.942 & $-7.03 * * \star$ \\
\hline
\end{tabular}

D. UNASSIGN/LINK

\begin{tabular}{rr}
\hline RRR & t-ratio \\
\hline 0.948 & -0.17 \\
0.871 & -0.42 \\
1.055 & 0.37 \\
0.378 & -3.43 *** \\
0.936 & -0.54 \\
0.734 & -2.48 ** \\
0.742 & -3.06 *** \\
1.648 & 1.17 \\
0.471 & -3.67 *** \\
0.891 & -0.41 \\
1.067 & 5.89 ***
\end{tabular}

F. UNASSIGN/ESTBL

\begin{tabular}{cc}
\hline RRR & t-ratio \\
\hline 0.404 & -3.24 \\
0.419 & $-2.87 * \star \star$ \\
1.426 & $2.95 * \star \star$ \\
1.124 & 0.58 \\
0.749 & $-2.70 * \star$ \\
0.805 & $-2.00 * \star$ \\
1.195 & $2.12 * \star$ \\
1.725 & 1.53 \\
0.852 & -0.92 \\
1.959 & $2.93 * \star \star$ \\
1.007 & 0.81
\end{tabular}

